\title{
Cingulotomy for medically refractory cancer pain
}

\author{
Ashwin Viswanathan, M.D., ${ }^{1}$ Viraat Harsh, M.B.B.S., ${ }^{1}$ Erlick A. C. Pereira, D.M., ${ }^{2}$ \\ And Tipu Z. Aziz, F.Med.Sci. ${ }^{2}$ \\ ${ }^{I}$ Department of Neurosurgery, Baylor College of Medicine, Houston, Texas; and ${ }^{2}$ Oxford Functional \\ Neurosurgery, Department of Neurosurgery, John Radcliffe Hospital, Oxford University Hospitals, Oxford, \\ United Kingdom
}

\begin{abstract}
Object. Cingulotomy has been reported in the literature as a potential treatment option for refractory cancerrelated pain. However, the optimal candidates for this intervention and the outcomes are not well characterized. The goal of this study was to review the available literature on cingulotomy, specifically for cancer-related pain.

Methods. A search of PubMed, PubMed Central, the Cochrane Library, and MEDLINE was performed to identify all articles discussing cingulotomy for cancer pain. The text strings "cingul*" and "pain" were separated by the Boolean AND operator, and used to perform the query on PubMed. Only studies in which a stereotactic technique was used, as opposed to an open technique, and specifically detailing outcomes for cancer pain were included. For centers with multiple publications, care was taken not to double-count individual patients.

Results. The literature review revealed only 8 unique studies describing outcomes of stereotactic cingulotomy for cancer pain. Between $32 \%$ and $83 \%$ of patients had meaningful pain relief. The location of the lesion was variable, ranging between $1 \mathrm{~cm}$ and $4 \mathrm{~cm}$ posterior to the tip of the anterior horn. Although serious adverse events are rare, a decline in focused attention can been seen in the early postoperative period, along with apathy and decreased activity.

Conclusions. For patients with cancer pain with diffuse pain syndromes, head and neck malignancies, and significant emotional distress, cingulotomy may be a safe treatment option with minimal cognitive changes. (http://thejns.org/doi/abs/10.3171/2013.6.FOCUS13236)
\end{abstract}

KEY WoRdS - cingulotomy • cancer pain • ablative therapy

A SUBSET of patients with cancer have pain that is refractory to multimodal noninterventional therapies. ${ }^{11,13}$ In this group of patients, interventional therapies such as neuroablation or intrathecal drug delivery can be considered. Neuroablation in the form of percutaneous cordotomy or myelotomy can be an effective intervention for cancer pain. ${ }^{9}$ However, patients with widespread pain and those with a significant psychological component to their pain may not be appropriate candidates for these interventions. Several reports have described the effectiveness of cingulotomy in treating refractory cancer pain. However, the role of this procedure in today's framework for the management of cancer pain is not well understood. The goal of this review was to review the existing literature and provide a framework for further studies of cingulotomy for cancer pain.

\section{Anatomical Basis}

The cingulate gyrus is located on the medial part of

Abbreviations used in this paper: $\mathrm{ACC}=$ anterior cingulate cortex; $\mathrm{PCC}=$ posterior cingulate cortex. the cerebral hemispheres and travels around the corpus callosum, separated from it by the pericallosal sulcus. Studies have demonstrated that the cingulate gyrus serves a role in the processing of cognitive, motor, emotional, pain, and visuospatial functions. ${ }^{20}$ The cingulate gyrus can be broadly divided into the ACC and the PCC, which have differing patterns of projection and cytoarchitecture. ${ }^{4}$ The ACC, which is thought to play a dominant role in cognitive and emotional processing, is also involved with the descending modulation of pain. ${ }^{19}$

Neuroimaging studies with functional MRI, PET, and SPECT have supported the view that the ACC helps in modulation of nociceptive information in somatosensory areas. ${ }^{6,15}$ Although the exact pathophysiological role of the ACC in pain perception is not completely understood, it is accepted that the ACC and its connections with the prefrontal cortex play an important role in emotional response to pain. Particularly, the ACC helps determine how pain is perceived rather than how it is sensed.${ }^{17}$ Brodmann areas 24a, 24b, and 25 in the ventral ACC also have connections to the amygdala, striatum, and thalamic nuclei, suggesting its roles in the processing of emotions, behavior, and motivational states. ${ }^{14}$ 
These findings have supported the physiological basis for lesioning the cingulate gyrus in the treatment of both psychiatric and pain disorders. Early studies of cingulotomy for psychiatric illness found that certain patients would have relief of intractable pain conditions and alleviation of withdrawal symptoms from opioid use. ${ }^{3}$ This furthered the concept of cingulotomy in the treatment of intractable pain, and particularly pain conditions with a significant emotional component.

\section{Methods}

A search of PubMed, PubMed Central, the Cochrane Library, and MEDLINE was performed to identify all articles discussing cingulotomy for cancer pain. The text strings "cingul"" and "pain" were separated by the Boolean AND operator, and used to perform the query on PubMed (command/ cingul*[title] AND pain[title]). Only studies using a stereotactic technique, as opposed to an open one, and specifically detailing outcomes for cancer pain were included. For centers with multiple publications, care was taken not to double-count individual patients.

\section{Results}

\section{Identification of Relevant Studies}

The initial literature search yielded 124 results. A careful review of the titles, abstracts, and (where needed) the manuscript helped us to determine that 112 articles were not relevant to this review, because they did not focus on stereotactic cingulotomy, or they focused on noncancer pain. An additional 4 studies either did not include adequate outcomes assessment ${ }^{2}$ or contained patients whose cases were republished at a later date. ${ }^{10}$ This left 8 studies that fit our inclusion criteria (Table 1).

\section{Operative Techniques}

A number of techniques for stereotactic cingulotomy have been reported in the literature. Early reports of cingulotomy used air ventriculograms to delineate the cerebral anatomy. Bur holes were placed $1.3 \mathrm{~cm}$ from the midline and $9 \mathrm{~cm}$ posterior to the nasion. A specially designed ventricular needle, which could also be used to perform the thermocoagulation, was then inserted into the frontal horn of the lateral ventricles. After needle insertion, 5-15 $\mathrm{cm}^{3}$ of air was injected, and radiographic studies were performed to delineate the ventricular anatomy. Lesions were made variably between $1 \mathrm{~cm}$ and $4 \mathrm{~cm}$ posterior to the anterior tip of the frontal horn, approximately $5 \mathrm{~mm}$ from the midline. ${ }^{2,8}$

With increasing imaging capabilities and the advent of a stereotactic frame, cingulotomy could be performed more precisely with the aid of MRI guidance. ${ }^{10}$ In the technique published by Hassenbusch et al.. ${ }^{10}$ the BrownRoberts-Wells stereotactic frame was secured to the patient after local anesthesia was induced, and a 1.5-T MRI study was performed with the head frame in place. The target for the cingulotomy was selected as $24 \mathrm{~mm}$ posterior to the anterior extent of the frontal horn, and the center of the cingulate gyrus was identified at this level. A radiofrequency electrode with a $10-\mathrm{mm}$ exposed tip was then advanced so that the center of the exposed tip was at the target. A single lesion was made bilaterally at $75^{\circ} \mathrm{C}$ for 60 seconds each.

The senior author (T.Z.A.) has used a CT-MRI fusion technique (Fig. 1). On the day of the procedure, the patient is given $10 \mathrm{mg}$ of intravenous dexamethasone, and the Cosman-Roberts-Wells frame is applied. A stereotactic CT scan is then performed and fused to a preoperatively obtained MRI study. The target is selected as 20 $\mathrm{mm}$ posterior to the tip of the frontal horn of the lateral ventricle, $10 \mathrm{~mm}$ from midline, and 1-2 $\mathrm{mm}$ above the roof of the lateral ventricle. Two radiofrequency lesions are performed on each side at $80^{\circ} \mathrm{C}$ for 90 seconds each by using a radiofrequency electrode with a $10-\mathrm{mm}$ exposed tip. After the first lesion, the radiofrequency electrode is withdrawn by $10 \mathrm{~mm}$ to perform the second lesion. A third lesion can be considered targeting the more lateral cingulum. The procedure is performed under local anesthesia, and via a twist drill hole placed $1.5 \mathrm{~cm}$ from midline at the level of the coronal suture.

\section{Postoperative Outcomes}

One of the earliest studies of cingulotomy for pain was Foltz and White's report on the treatment of 6 patients with cancer-related pain in $1962 .{ }^{8}$ The patients had strong emotional factors associated with their pain including anxiety and depression, which augmented their symptoms. Pain locations included the face and neck (3 patients), back and hip (2 patients), and shoulder and arm (1 patient). Of this group, 2 patients had excellent results, 3 had good results, and in 1 the results were fair. Two patients underwent a unilateral cingulotomy and the other patients underwent bilateral cingulotomies. Postoperatively, patients did not experience significant withdrawal symptoms despite abrupt cessation of opioids.

In 1971, Faillace et al. described the outcomes in 7 patients with cancer pain who underwent cingulotomy? All the patients with cancer pain had significant emotional factors that contributed to their pain. The target was $3.5-4 \mathrm{~cm}$ posterior to the tip of the frontal horn, which was reached using a surgical technique similar to that of Foltz and White. Three of the 7 patients had improvement in their pain that lasted for 3 days to 3 months. The other 4 patients did not experience improvement. The authors also reported the cognitive outcomes of their patients and found a significant decrease in performance on a nonverbal ordering test. Overall, however, the cognitive outcomes did not show significant changes from baseline.

The largest series of cingulotomy for cancer pain was published by Hurt and Ballantine in 1974. ${ }^{12}$ The authors treated 32 patients with advanced cancer who had a range of cancers including lung, gastrointestinal, head, neck, melanoma, and sarcoma. In their series, $32 \%$ of patients had either complete or marked pain relief, $19 \%$ had moderate pain relief, and $44 \%$ had slight or no relief. There were no deaths in their series. Transient headache and fever were noted, and less commonly bladder or bowel incontinence and confusion were noted. These symptoms did not persistent beyond the 2nd postoperative week. Voris and Whisler ${ }^{21}$ reported their experience with stereo- 


\section{Cingulotomy for cancer pain}

TABLE 1: Literature review of stereotactic cingulotomy for cancer-related pain*

\begin{tabular}{|c|c|c|c|c|}
\hline Authors \& Year & $\begin{array}{l}\text { No. of } \\
\text { Pts }\end{array}$ & Procedure/Target & Outcome & Follow-Up \\
\hline Foltz \& White, 1962 & 6 & $\begin{array}{l}\text { unilat or bilat air ventriculography-guided cingu- } \\
\text { lotomy (1-2.5 cm pst to tip of frontal horn) }\end{array}$ & $83 \%$ good or excellent outcome & 4 days -9 mos \\
\hline Faillace et al., 1971 & 7 & $\begin{array}{l}\text { bilat stereotactic cingulotomy (3.5-4 cm pst to tip } \\
\text { of frontal horn) }\end{array}$ & $\begin{array}{l}45 \% \text { improvement lasting from } 3 \text { days to } \\
3 \text { mos }\end{array}$ & $>2 \mathrm{yrs}$ \\
\hline Hurt \& Ballantine, 1974 & 32 & $\begin{array}{l}\text { stereotactic ant cingulate lesion }(2-4 \mathrm{~cm} \text { pst to tip } \\
\text { of frontal horn); } 1 \text { lesion } 2 \mathrm{~cm} \text { above ventricle } \\
\text { roof } \& 1 \text { lesion } 1 \mathrm{~cm} \text { below the first }\end{array}$ & $\begin{array}{l}9 \% \text { complete relief; } 23 \% \text { marked relief; } 19 \% \\
\text { moderate relief; } 44 \% \text { slight or no relief }\end{array}$ & $<3 \mathrm{mos}$ \\
\hline Voris \& Whisler, 1975 & 5 & $\begin{array}{l}\text { bilat stereotactic cingulotomy (separate lesions } 13 \\
\& 17 \mathrm{~mm} \text { pst to tip of frontal horn, } 12 \mathrm{~mm} \text { from } \\
\text { midline, } 6 \mathrm{~mm} \text { above ventricle) }\end{array}$ & all had pain relief until death & $1-12$ mos \\
\hline $\begin{array}{l}\text { Pillay \& Hassenbusch, } \\
\quad 1992\end{array}$ & 9 & $\begin{array}{l}\text { MRI-guided stereotactic cingulotomy }(24 \mathrm{~mm} \text { pst } \\
\text { to tip of frontal horn, CCG chosen as target); } 1 \\
\text { lesion made on each side }\left(75^{\circ} \mathrm{C} \text { for } 60 \mathrm{sec}\right)\end{array}$ & $\begin{array}{l}\text { pain relief: excellent, 4; good, 2; fair, 1; } \\
\text { poor, } 2\end{array}$ & $1 \mathrm{yr}$ \\
\hline Wong et al., 1997 & 3 & $\begin{array}{l}\text { MRI-guided stereotactic cingulotomy ( } 24 \mathrm{~mm} \text { pst } \\
\text { to tip of frontal horn, CCG chosen as target); } 1 \\
\text { lesion made on each side }\end{array}$ & 2 of 3 pts had excellent outcome & NA \\
\hline \multirow[t]{2}{*}{ Yen et al., 2005} & \multirow[t]{2}{*}{15} & \multirow{2}{*}{$\begin{array}{l}\text { stereotactic bilat ant cingulotomy ( } 24 \mathrm{~mm} \text { pst to } \\
\text { tip of frontal horn); } 1-2 \text { lesions made on each } \\
\text { side }\left(80^{\circ} \mathrm{C} \text { for } 80 \mathrm{sec}\right)\end{array}$} & $\begin{array}{l}53 \% \text { significant pain relief; } 27 \% \text { meaningful } \\
\text { pain relief; } 20 \% \text { no relief }\end{array}$ & 1 wk \\
\hline & & & $\begin{array}{l}33 \% \text { significant pain relief; } 25 \% \text { meaningful } \\
\text { pain relief; } 42 \% \text { no relief }\end{array}$ & $3 \mathrm{mos}$ \\
\hline Yen et al., 2009 & 10 & $\begin{array}{l}\text { stereotactic bilat ant cingulotomy ( } 24 \mathrm{~mm} \text { pst to } \\
\text { tip of frontal horn); } 1-2 \text { lesions made on each } \\
\text { side }\left(80^{\circ} \mathrm{C} \text { for } 80 \mathrm{sec}\right)\end{array}$ & $\begin{array}{l}40 \% \text { of pts had }>75 \% \text { relief; } 20 \% \text { of pts had } \\
25-75 \% \text { relief; \& } 40 \% \text { of pts had }<25 \% \\
\text { relief }\end{array}$ & $\begin{array}{l}\text { assessment at } 1 \text { wk } \\
\quad \& 3 \text { mos postop }\end{array}$ \\
\hline
\end{tabular}

* Ant = anterior $;$ CCG = center of cingulated gyrus; $N A=$ not available; $p s t=$ posterior; $p$ ts = patients.

tactic intracranial lesioning in 90 patients in 1975. In their series, 5 patients underwent bilateral cingulotomy for the treatment of cancer pain. These investigators followed a technique similar to that of Foltz and White, and separate coagulations were made $13 \mathrm{~mm}$ and $17 \mathrm{~mm}$ posterior to the tip of the anterior horn. Over a follow-up period of 1-12 months, the authors reported that these 5 patients had pain relief until death.

Using modern MRI-guided stereotactic techniques, Pillay and Hassenbusch ${ }^{16}$ reported their results in 9 patients with cancer-related pain who underwent cingulotomy. The median preoperative numerical pain score was 9 , and the median postoperative numerical pain score was 4. One patient developed postoperative global aphasia, which resolved by 10 days after surgery. Postoperatively each patient's analgesic dose requirement markedly decreased. In addition, the authors reported improved cognition, especially concentration and perception, and there were no changes in or flattening of affect. In 1997, an additional 3 patients were reported from the MD Anderson Cancer Center, 2 of whom had excellent pain outcomes. ${ }^{23}$ The third patient's postoperative course was complicated by a flattened affect and paranoid ideations. She also did not have significant benefit with regard to pain.

Most recently, Yen et al. ${ }^{25}$ detailed their experience treating 15 patients who had refractory cancer pain with bilateral anterior cingulotomy between August 2001 and December 2002. The target chosen was $24 \mathrm{~mm}$ posterior to the anterior tip of the frontal horn of the lateral ventri- cle. Bur holes were placed $2 \mathrm{~cm}$ lateral to the midline, and 1 or 2 lesions were made $3 \mathrm{~mm}$ apart bilaterally by using a 2-mm exposed tip radiofrequency electrode at $80^{\circ} \mathrm{C}$ for 80 seconds. In the week following surgery, 8 patients $(53 \%)$
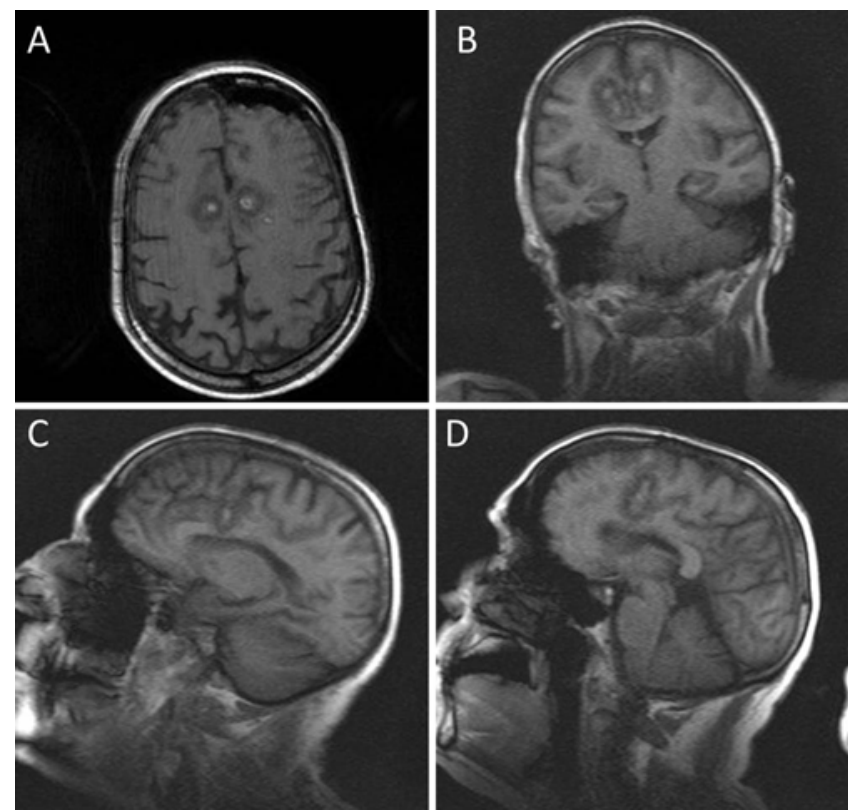

FIG. 1. Brain T1-weighted MRI studies showing bilateral anterior cingulotomies: axial (A), coronal (B), parasagittal (C), and sagittal (D). 


\section{A. Viswanathan et al.}

reported significant pain relief, 4 patients (27\%) reported meaningful relief, and 3 patients (20\%) reported little improvement. Sixty-six percent of patients with cancer pain showed definite pain relief at the 1-month follow-up, which decreased to $50 \%$ at 6 months. An additional series of 10 patients with cancer pain, who were treated between September 2002 and April 2004, was reported by the authors in $2009 .{ }^{24}$ In this group, $40 \%$ of patients had greater than $75 \%$ pain relief, and an additional 2 patients had between $25 \%$ and $75 \%$ pain relief. This result was seen at both 1 week postoperatively and at the 3 -month follow-up.

In their report from 2009, Yen et al. ${ }^{24}$ also reported the impact of bilateral cingulotomy on cognition in 10 patients with intractable pain. Neuropsychological assessments were performed 1 day before surgery and at 1 week and 1 month postoperatively. There were no notable effects on cognitive functions including language, memory, intellect, and motor and visual-constructional skills. There was, however, a decline in focused attention performance in the early postoperative period as determined by the Stroop interference test. Two patients with good pain relief developed transient and self-resolving inappropriate and uninhibited speech for 2 days.

Adverse events reported include rare transient postoperative spasticity and hemiparesis, bleeding, transient postoperative confusion, ataxia, mild weight gain, transient bowel and bladder incontinence, seizures, increased appetite, decreased memory, and in a very few cases, cardiovascular complications. Headache, nausea, fever, and urinary incontinence may last for up to 48 hours. No deaths or infections were reported in a review of 800 cingulotomies performed at the Massachusetts General Hospital, although $1 \%$ of the patients had a seizure postoperatively. ${ }^{1,5}$ Frontal syndromes including apathy and decreased activity and spontaneity have been more frequently reported.22 Significant neurocognitive defects are rare, but have been reported..$^{18}$

\section{Discussion}

Despite increasing multidisciplinary efforts to treat cancer pain, there is a subset of patients who suffer. Using CT guidance has made neuroablative techniques such as cordotomy and myelotomy safer and more effective. These interventions can be considered early in the pain management algorithm for patients with unilateral nociceptive pain (cordotomy) or visceral midline pain (myelotomy). The use of neuromodulation in the form of intrathecal drug delivery is another option for the management of cancer pain, especially in patients with multiple pain sites. Opioids (either alone or in combination with local anesthetic agents) or the use of ziconotide can be effective, especially in patients who have side effects associated with the systemic administration of opioids.

In advanced cancer, however, it is not uncommon to see patients with diffuse pain syndromes, head and neck malignancies, and significant emotional distress associated with their pain. These are patients who will most likely not benefit from cordotomy, myelotomy, or intrathecal opioids. In these patients approaches such as cingulotomy could be considered.

\section{Conclusions}

The present literature supports the conclusion that bilateral stereotactic cingulotomy can be performed safely with minimal noticeable cognitive changes. Further controlled studies are warranted to determine the role of cingulotomy in the management of refractory cancer pain.

\section{Disclosure}

The authors report no conflict of interest concerning the materials or methods used in this study or the findings specified in this paper.

Author contributions to the study and manuscript preparation include the following. Conception and design: Viswanathan. Drafting the article: Viswanathan, Harsh, Pereira. Critically revising the article: Viswanathan, Harsh, Pereira. Reviewed submitted version of manuscript: all authors.

\section{References}

1. Abdelaziz OS, Cosgrove GR: Stereotactic cingulotomy for the treatment of chronic pain, in Burchiel KJ (ed): Surgical Management of Pain. New York: Thieme, 2002, pp 812-820

2. Ballantine HT Jr, Cassidy WL, Flanagan NB, Marino R Jr: Stereotaxic anterior cingulotomy for neuropsychiatric illness and intractable pain. J Neurosurg 26:488-495, 1967

3. Brotis AG, Kapsalaki EZ, Oaterakis K, Smith JR, Fountas $\mathrm{KN}$ : Historic evolution of open cingulectomy and stereotactic cingulotomy in the management of medically intractable psychiatric disorders, pain and drug addiction. Stereotact Funct Neurosurg 87:271-291, 2009

4. Bush G, Luu P, Posner MI: Cognitive and emotional influences in anterior cingulate cortex. Trends Cogn Sci 4:215-222, 2000

5. Cosgrove GR, Rauch SL: Stereotactic cingulotomy. Neurosurg Clin N Am 14:225-235, 2003

6. Crottaz-Herbette S, Menon V: Where and when the anterior cingulate cortex modulates attentional response: combined fMRI and ERP evidence. J Cogn Neurosci 18:766-780, 2006

7. Faillace LA, Allen RP, McQueen JD, Northrup B: Cognitive deficits from bilateral cingulotomy for intractable pain in man. Dis Nerv Syst 32:171-175, 1971

8. Foltz EL, White LE Jr: Pain "relief" by frontal cingulumotomy. J Neurosurg 19:89-100, 1962

9. Harsh V, Viswanathan A: Surgical/radiological interventions for cancer pain. Curr Pain Headache Rep 17:331, 2013

10. Hassenbusch SJ, Pillay PK, Barnett GH: Radiofrequency cingulotomy for intractable cancer pain using stereotaxis guided by magnetic resonance imaging. Neurosurgery 27:220-223, 1990

11. Healthways: Care Guide: Cancer Pain. Science and Medical Integrity, 2010 (https://host1.medcohealth.com/art/corporate/ pdf/Cancer_Pain_\%20Care_Guide.pdf) [Accessed July 12, 2013]

12. Hurt RW, Ballantine HT Jr: Stereotactic anterior cingulate lesions for persistent pain: a report on 68 cases. Clin Neurosurg 21:334-351, 1974

13. Lordon SP: Interventional approach to cancer pain. Curr Pain Headache Rep 6:202-206, 2002

14. Paus T: Primate anterior cingulate cortex: where motor control, drive and cognition interface. Nat Rev Neurosci 2:417-424, 2001

15. Peyron R, Laurent B, García-Larrea L: Functional imaging of brain responses to pain. A review and meta-analysis (2000). Neurophysiol Clin 30:263-288, 2000

16. Pillay PK, Hassenbusch SJ: Bilateral MRI-guided stereotactic cingulotomy for intractable pain. Stereotact Funct Neurosurg 59:33-38, 1992 


\section{Cingulotomy for cancer pain}

17. Rolls ET, O'Doherty J, Kringelbach ML, Francis S, Bowtell R, McGlone F: Representations of pleasant and painful touch in the human orbitofrontal and cingulate cortices. Cereb Cortex 13:308-317, 2003

18. Sweet WH, Obrador Alcalde S, Martin-Rodriguez JG: Neurosurgical Treatment in Psychiatry, Pain, and Epilepsy. Baltimore: University Park Press, 1977

19. Tracey I, Mantyh PW: The cerebral signature for pain perception and its modulation. Neuron 55:377-391, 2007

20. Vogt BA, Nimchinsky EA, Vogt LJ, Hof PR: Human cingulate cortex: surface features, flat maps, and cytoarchitecture. J Comp Neurol 359:490-506, 1995

21. Voris HC, Whisler WW: Results of stereotaxic surgery for intractable pain. Confin Neurol 37:86-96, 1975

22. Wilkinson HA, Davidson KM, Davidson RI: Bilateral anterior cingulotomy for chronic noncancer pain. Neurosurgery 45: 1129-1136, 1999

23. Wong ET, Gunes S, Gaughan E, Patt RB, Ginsberg LE, Has- senbusch SJ, et al: Palliation of intractable cancer pain by MRI-guided cingulotomy. Clin J Pain 13:260-263, 1997

24. Yen CP, Kuan CY, Sheehan J, Kung SS, Wang CC, Liu CK, et al: Impact of bilateral anterior cingulotomy on neurocognitive function in patients with intractable pain. J Clin Neurosci 16: 214-219, 2009

25. Yen CP, Kung SS, Su YF, Lin WC, Howng SL, Kwan AL: Stereotactic bilateral anterior cingulotomy for intractable pain. J Clin Neurosci 12:886-890, 2005

Manuscript submitted May 15, 2013.

Accepted June 26, 2013.

Please include this information when citing this paper: DOI: 10.3171/2013.6.FOCUS13236.

Address correspondence to: Ashwin Viswanathan, M.D., Baylor College of Medicine, 1709 Dryden St., Houston, TX 77030. email: ashwinv@bcm.edu. 